\title{
Weathering Resistance of Waterborne Polyurethane Coatings Reinforced with Silica from Rice Husk Ash
}

\author{
WESLEY F. MONTEIRO ${ }^{1 *}$, GABRIELA M. MIRANDA ${ }^{1 *}$, RAFAEL R. SOARES ${ }^{1}$, CLÁUDIA A.B. DOS SANTOS ${ }^{1}$, \\ MAURÍCIO S. HOFFMANN ${ }^{1}$, CARLOS L.P. CARONE ${ }^{4}$, VIVIANE DE LIMA ${ }^{4}$, MILTON F. DE SOUZA ${ }^{5}$, \\ ADRIANO D. CAMPANI ${ }^{6}$, SANDRA M.O. EINLOFT ${ }^{1,2}$, JEANE E. DE LIMA ${ }^{1,3}$ and ROSANE A. LIGABUE ${ }^{1,3}$ \\ 'Graduate Program in Materials Engineering and Technology, PUCRS, Av. \\ Ipiranga, 6681, Partenon, 90619-900 Porto Alegre, RS, Brazil \\ ${ }^{2}$ School of Technology, PUCRS, Av. Ipiranga, 6681, Partenon, 90619-900 Porto Alegre, RS, Brazil \\ ${ }^{3}$ School of Science, PUCRS, Av. Ipiranga, 6681, Partenon, 90619-900 Porto Alegre, RS, Brazil \\ ${ }^{4}$ Institute of Exact and Technological Science, FEEVALE, ERS-239, 2755, 93525-075 Novo Hamburgo, RS, Brazil \\ ${ }^{5}$ Institute of Physics, USP, Av. Trab. São Carlense, 400, Parque Arnold Schimidt, 13566-590 São Carlos, SP, Brazil \\ ${ }^{6}$ NokXeller Microdispersions S.A., Rua Caí, 711, Vila Princesa Izabel, 94940-030 Cachoeirinha, RS, Brazil
}

Manuscript received on November 9, 2018; accepted for publication on February 5, 2019

\begin{abstract}
How to cite: MONTEIRO WF, MIRANDA GM, SOARES RR, SANTOS CAB, HOFFMANN MS, CARONE CLP, LIMA V, SOUZA MF, CAMPANI AD, EINLOFT SMO, LIMA JE AND LIGABUE RA. 2019. Weathering Resistance of Waterborne Polyurethane Coatings Reinforced with Silica from Rice Husk Ash. An Acad Bras Cienc 91: e20181190. DOI 10.1590/0001-3765201920181190.
\end{abstract}

\begin{abstract}
Waterborne polyurethanes (WPUs) are interesting materials for coatings when compared to solvent-based polyurethanes, once that reducing the concentration of volatile organic compounds that are harmful for human health and the environment. However, the WPU has low weathering resistance. In order to improve this behavior among others properties, inorganic fillers has been added in these systems. $\mathrm{SiO}_{2}$ particles from various sources, mainly, from agro-industrial waste, as rice husk has attracted the scientific and technological interest. In this study, the accelerated weathering essay was performed in waterborne polyurethane (WPU)/ silica (from rice husk ash) composites in order to evaluate the thermal and physical changes in these materials. These composites were prepared by two distinct methods: in situ polymerization and blending method. The highest resistance to thermal degradation and to accelerated weathering was reached with WPU/silica composites obtained by blending method due the interactions between $\mathrm{SiO}_{2}$ particles and the polymer matrices. Blending method for preparation WPU/silica composites proved to be a simpler and faster method, with no drawback for large scale application.
\end{abstract}

Key words: waterborne polyurethane, rice husk ash, silica, accelerated weathering resistance.

\section{INTRODUCTION}

Polyurethanes are segmented polymers formed by hard and soft segment with great scientific

Correspondence to: Rosane Angelica Ligabue

E-mail: rligabue@pucrs.br

ORCid: https://orcid.org/0000-0002-7086-8820

*These authors contributed equally to this work and technological interest being widely used in applications such as coatings, adhesives, foams, elastomers and biomaterials (Pácios et al. 2013, Ren and Frazier 2013, Fiorelli et al. 2016). However, conventional polyurethanes have been replaced for waterborne polyurethanes (WPU) due to the volatile organic compounds released that are 
toxic and harmful to humans and the environment (Gurunathan and Chung 2017, Yang et al. 2017, Chai et al. 2018). Generally, WPUs show a good flexibility due the specific microstructure formed by soft segments that provide elastomeric characteristics while the hard segments can provide polar urethane linkages ( $\mathrm{Li}$ and Shan 2018).

In the last years, the use of WPU composites with inorganic fillers has grown significantly as a way of overcoming the WPU disadvantages (i.e. low thermal and mechanical resistance) over conventional polyurethanes (Bhargava et al. 2015, Soares et al. 2014, Sung and Kim 2017, Zhang et al. 2011). Another disadvantage is the low hydrolysis resistance of WPU, especially when applied to external coatings. Therefore, the filler addition can promote the improvement of thermal and mechanical properties, as well as hydrolysis resistance when under weathering (Liao et al. 2015, Fan et al. 2015, Bastürk et al. 2016). The weathering exposure in the PU matrix can provoke many degradation processes such as oxidation, chain scission and crosslinking, which cause modifications in the structural characteristics. The UV radiation on the PU surface can cause the oxidation of methylene ( $\alpha$-position) and $-\mathrm{NH}$ groups. After, this process can lead to formation of hydroperoxides, secondary peroxides and carbamic acid among others. These changes can decrease mechanical properties and brightness of PU coatings. In addition, it can increase the cracking process and the possibility of filler migration in the coating surface (Das et al. 2017a, b, Jacobs et al. 2016).

Recently, inorganic fillers such as titanium dioxide, zinc oxide, silica and manganese dioxide have received special attention, due the improve in UV-resistance and mechanical properties of the polymer matrix (Das et al. 2017a, Jofre-Reche et al. 2017).

Amorphous silica $\left(\mathrm{SiO}_{2}\right)$ is a filler widely used in polymer composites due to their excellent properties such as high temperature resistance, UV radiation resistance, corrosion and excellent mechanical properties (Bastürk et al. 2016, Sadeghi et al. 2013, Cakic et al. 2016, Seyfi et al. 2016, Heidarian et al. 2010).

In polymer composites, the homogeneous distribution and compatibility of inorganic filler with the polymer matrix can be difficult to achieve, which limits its application. These features are dependent of the obtainment method of composites. Physical mixture (blending method) and in situ polymerization are methods used in the preparation of composites (Seyfi et al. 2016, Prado et al. 2015, Thomas et at. 2017, Monteiro et al. 2018). The use of different preparation methods provides changes in the conformation of the cross-linked bonds in macromolecular level of the PU chain (Thomas et al. 2017, Monteiro et al. 2016, Lv et al. 2012) providing improvements in the properties of composite. The addition of amorphous $\mathrm{SiO}_{2}$ is a possibility for improving the weathering performance of organic coatings. Due the low refractive index (1.46) of this filler, its incorporation doesn't change the PU coating transparency (Thomas et al. 2017).

In this context, this study goals to prepare WPU composites with high weathering resistance, using filler silica obtained from rice husk ash.

\section{MATERIALS AND METHODS}

\section{MATERIALS}

The polyurethane was obtained by the reaction of a commercial polyol (polyester linear, Covestro, $\mathrm{MM}=1000 \mathrm{~g} \cdot \mathrm{mol}^{-1}$ ), isophorone diisocyanate (IPDI, Covestro) at molar ratio $\mathrm{NCO} / \mathrm{OH}=1.7$ and 2,2-bis (hydromethyl) propionic acid (DMPA, Perstorp) as internal surfactant. Hydrazine monohydrated was used as chain extender (Merck) and triethylamine (TEA, Covestro) to neutralize the acid groups of the DMPA. Silica $\left(\mathrm{SiO}_{2}\right)$ obtained from rice husk ash was generously provided by the Institute of Physics/USP. 


\section{PREPARATION OF THE WPU/SIO 2 COMPOSITES}

In the composites preparation (blending method and in-situ polymerization) 1,3 and $5 \% \mathrm{w} / \mathrm{w}$ of $\mathrm{SiO}_{2}$ were used in relation to the prepolymer weight. The WPU/silica composites (CP) were named as: CP1 when were prepared by in situ polymerization and CP2 when were prepared by blending method, and $1 \%, 3 \%$ and $5 \%$ corresponding to the $\mathrm{SiO}_{2}$ contents.

\section{In-situ POLYMERIZATION}

Initially, $50 \mathrm{~g}$ of polyol was added in a Becker, followed by addition of determinated amount of filler. This mixture was kept under ultrasonification bath (UltraCleaner 1450) for $15 \mathrm{~min}$. These homogeneous suspensions were poured into the reactor along with the remaining polyol, IPDI and DMPA. The formation reaction of the NCO terminated-prepolymer was kept under constant stirring at $80{ }^{\circ} \mathrm{C}$ for $1 \mathrm{~h}$ After, TEA content (molar equivalent to the DMPA) was added into the reactor and kept under stirring for 30 minutes at 50 ${ }^{\circ} \mathrm{C}$. The free isocyanate residual was monitored by titration with $n$-dibutylamine based on the ASTM 2572 standard technique. Finally, the prepolymer was dispersed in water with hydrazine (molar equivalent to the free $\mathrm{NCO}$ residual) and kept under vigorous stirring $(800 \mathrm{rpm})$ at room temperature for 30 minutes to get a WPU with $37 \%$ solids content. Calculated hard segment (HS) percentage and reactants amount for each composites CP1 and pure PU are shown in the Table I.

\section{BLENDING METHOD}

In this case, it was prepared waterborne polyurethane without filler (pure PU) as described in in situ polymerization. Thus, this pure PU dispersion was divided into 3 same parts for the addition of different filler amounts. The appropriate amount of $\mathrm{SiO}_{2}(1$, 3 or $5 \% \mathrm{w} / \mathrm{w}$ ) was suspended in the dispersions by ultrasonication bath (UltraCleaner 1450) for 30 minutes to get a $\mathrm{PU} / \mathrm{SiO}_{2}$ aqueous dispersions (CP2 $1 \%, \mathrm{CP} 23 \%$ and $\mathrm{CP} 25 \% \mathrm{w} / \mathrm{w}$, respectively) by blending method with $37 \%$ solids content.

\section{PREPARATION OF THE FILM}

The obtained films of WPU/ $\mathrm{SiO}_{2}$ composites were prepared by casting method on a glass plate and dried under controlled temperature and humidity $\left(22 \pm 2^{\circ} \mathrm{C}\right.$ and $\left.40 \pm 5 \%\right)$ for a week. The films with approximately $700 \mu \mathrm{m}$ of thickness were stored in a desiccator at room temperature.

\section{CHARACTERIZATION}

Fourier Transform Infrared Spectroscopy (FTIR)

The evaluation of the interaction filler-polymer were performed by Fourier transform infrared spectroscopy (PerkinElmer spectrometer, Spectrum One model) from film samples in transmission mode in the range of $4000-650 \mathrm{~cm}^{-1}$.

\section{Differential Scanning Calorimetry (DSC)}

Differential scanning calorimetry (DSC equipment, Q20 model, TA Instruments) was used to determinate the glass transition temperature $\left(\mathrm{T}_{\mathrm{g}}\right)$

TABLE I

Reactants amounts and calculated hard segments (HS) for pure PU and the composites prepared by in situ polymerization (CP1).

\begin{tabular}{cccccc}
\hline Sample & Polyol (g) & IPDI (g) & DMPA (g) & Hydrazine (g) & HS (wt\%) \\
\hline Pure PU & 87.1 & 55.4 & 7.4 & 3.7 & 43.3 \\
CP1 1\% & 84.5 & 54.5 & 7.4 & 3.6 & 43.7 \\
CP1 3\% & 85.5 & 55.1 & 7.4 & 3.0 & 43.4 \\
CP1 5\% & 80.7 & 52.5 & 7.4 & 1.7 & 43.3 \\
\hline
\end{tabular}


and was performed $-90^{\circ} \mathrm{C}$ to $200^{\circ} \mathrm{C}$ (Heat/Cool/ Heat mode) at a heating rate of $10^{\circ} \mathrm{C} / \mathrm{min}$ under an inert atmosphere of nitrogen. The $\mathrm{T}_{\mathrm{g}}$ value was determined from the second heating scan in order to minimize specific thermal history of the synthesized polymer.

\section{Thermogravimetric Analysis (TGA)}

The thermal stability of pure polyurethane and the composites were evaluated by Thermogravimetric analysis (SDT equipment, Q600 model, TA Instruments). The analysis was carried out with a heating rate of $20^{\circ} \mathrm{C} / \mathrm{min}$, from room temperature to $800^{\circ} \mathrm{C}$ under inert nitrogen.

\section{Scanning Electron Microscope (SEM)}

Filler particles morphology and of the composites films were evaluated by field-emission scanning electron microscopy (FESEM) (Model FEI Inspect F50) and SE (secondary electron beam). The gold film was deposited on the samples by using an ionsputter. Average particle size was obtained from image of SEM and using Image Tool ${ }^{\mathrm{TM}}$ software from 25 measurements.

\section{Atomic Force Microscope (AFM)}

Roughness of the WPU and nanocomposites was characterized by analyzing the films by AFM. The analyses were performed in tapping mode to construct phase/height contrast images at various locations on the sample surface, using a Bruker Dimension Icon PT system and TAP150A probe (Bruker, resonance frequency of $150 \mathrm{kHz}$ and 5 N.m ${ }^{-1}$ spring constant). The equipment was calibrated prior to sample measurements.

\section{ACCELERATED WEATHERING TEST}

Accelerated weathering tests were performed using the QUV Accelerated Weathering equipment (Q-LAB Corporation) following the ASTM G53-
96 (UV light cycle at $50^{\circ} \mathrm{C}$ and condensation cycle at $40^{\circ} \mathrm{C}$ ). The film samples, $\mathrm{CP} 1$ and $\mathrm{CP} 21 \% \mathrm{w} / \mathrm{w}$ (96 $\mathrm{mm} \times 62 \mathrm{~mm} \times 0.10 \mathrm{~mm}$ ), were exposed to UVB-313 lamps (Q-LAB Corporation) with $0.7522 \mathrm{~W} / \mathrm{m}^{2} / \mathrm{nm}$ irradiance at $313 \mathrm{~nm}$, in total time of $672 \mathrm{~h}$. The samples were removed to each $134 \mathrm{~h}$ of exposure, and were characterized by DSC, TGA and SEM. Also, the surface specular gloss of the pure PU and composites films, before and after exposure, was evaluated and it was measured at $60^{\circ}$ of incidence with the aid of a portable Micro-tTRIglossmeter (BYK Gardner) according to ASTM D 523.

\section{RESULTS AND DISCUSSION}

\section{SEM ANALYSIS}

Amorphous silica $\left(\mathrm{SiO}_{2}\right)$ filler presents in the form of particles agglomerates with average size of $1.8 \mu \mathrm{m}$. The enlarged image of the $\mathrm{SiO}_{2}$ particles (Supplementary Material, Figure S1) shows these agglomerates are formed by small spherical particles with average particle size is around of 275 nm.

\section{FTIR ANALYSIS}

The interactions between filler and polymer matrix were evaluated by infrared spectroscopy. Fig. 1a and $2 \mathrm{a}$ show the absorption spectra (in absorbance) of pure PU, CP1 and CP2 composites. The absorption regions of the $\mathrm{NH}$ and $\mathrm{C}=\mathrm{O}$ groups (Figure 1b-1c and Figure 2b-2c, respectively) were evaluated because these groups are the most affected by the interaction filler-polymer according to the literature (Bao et al. 2017). The characteristic bands of the NH group appear in 3545 and 3350 $\mathrm{cm}^{-1}$ and corresponding respectively, to the free $\mathrm{NH}$ and bonded $\mathrm{NH}$ group. For CP1 samples, there was an increase of the absorption intensity of these bands (mainly, in $\approx 3350 \mathrm{~cm}^{-1}$ ) compared to the pure PU (WPU). Also, there was an increase in the intensity on band located at $1023 \mathrm{~cm}^{-1}$ can 


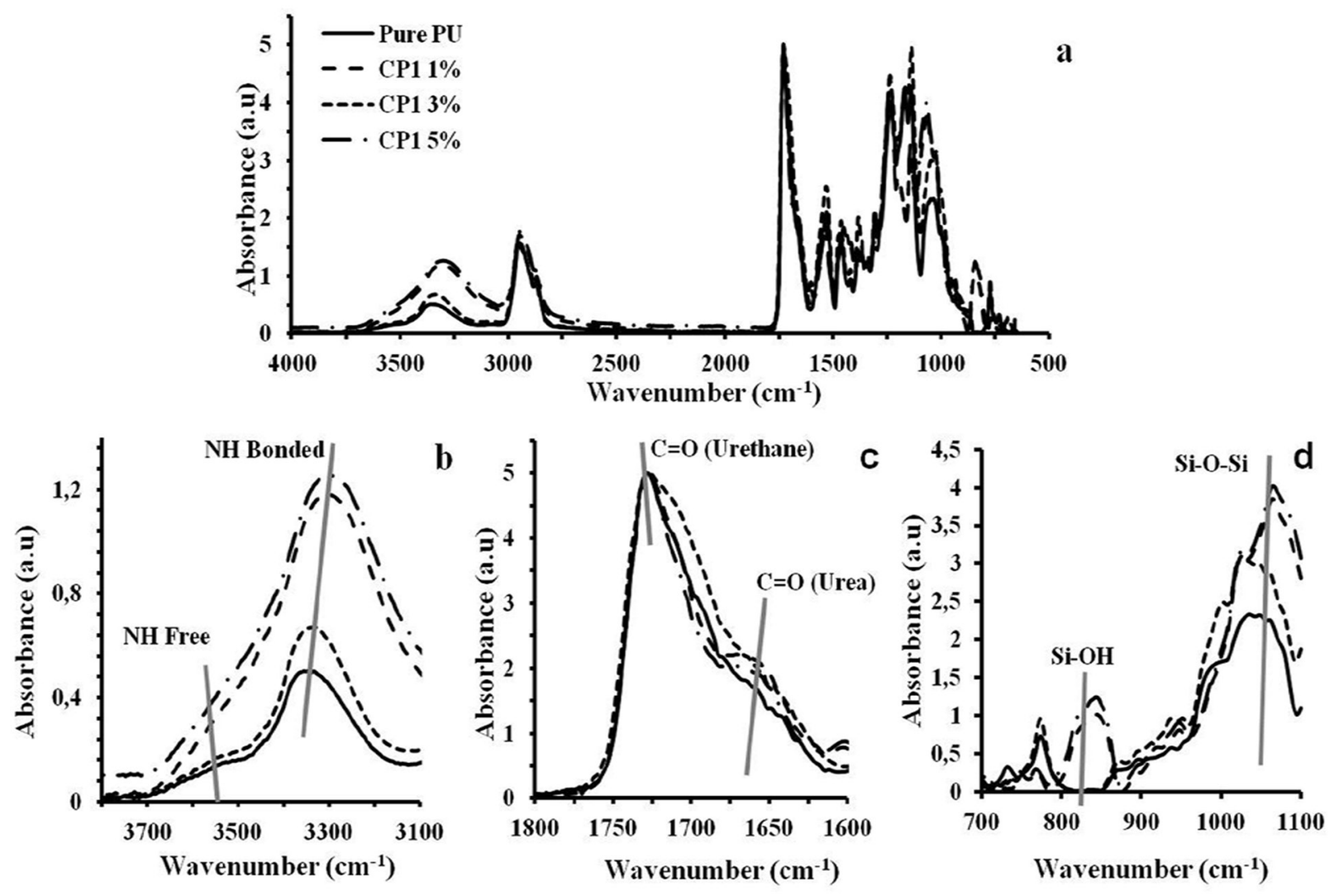

Figure 1 - FTIR spectra of the pure PU and CP1 composites (a); zoom in the region of $\mathrm{NH}$ band (b); zoom in the of $\mathrm{C}=\mathrm{O}$ band and (c) zoom in the region of Si-OH, Si-O-Si.

be related to $\mathrm{Si}-\mathrm{O}-\mathrm{Si}$ present in the composites. Besides that, the appearance of signal in $823 \mathrm{~cm}^{-1}$ corresponding to Si-OH vibration showed that not all hydroxyl groups on the surface of silica reacted (Peruzzo et al. 2016).

For CP2 samples (Figure 2), there was a progressively increase of the absorption intensity of bonded $\mathrm{NH}$ band with the addition of the filler. Moreover, it was observed, mainly in CP2 samples, a broadening of $\mathrm{C}=\mathrm{O}$ band (1730-1650 $\mathrm{cm}^{-1}$ interval) corresponding to urethane and urea bonds. It can be due to the kind of filler-polymer interaction (i.e. hydrogen bonds) formed between hydroxyl groups of the $\mathrm{SiO}_{2}$ either with the $\mathrm{C}=\mathrm{O}$ groups of the urethane (hard segments) or $\mathrm{C}=\mathrm{O}$ groups of the ester (soft segments) as described in the literature (Bao et al. 2017). Similar behavior was observed in a previous work of the group (Soares et al. 2014). Also, there was an increase in the signal corresponding to Si-O-Si $\left(1023 \mathrm{~cm}^{-1}\right)$ similar to CP1. According to Han et al. (2018), in the region near to $1100 \mathrm{~cm}^{-1}$, changes in the absorption intensity can occur with the increase of silica particles content, however, exist an overlapping of absorption peaks of Si-O-Si (asymmetric stretching) and C-O-C bonds (symmetric stretching), which can lead to the difficult in observe an increase in this band with filler content. Moreover, silica particles may to form agglomerates, leading a distribution not homogeneous in the polymer matrix during the formation process of coating film.

FTIR analyzes (Figures 1 and 2) showed that the $\mathrm{SiO}_{2}$ particles may to be interacting different ways with polymer chain. In the CP1 composites, the silica filler was added in the beginning of in situ polymerization, consequently, the $\mathrm{OH}$ groups of 

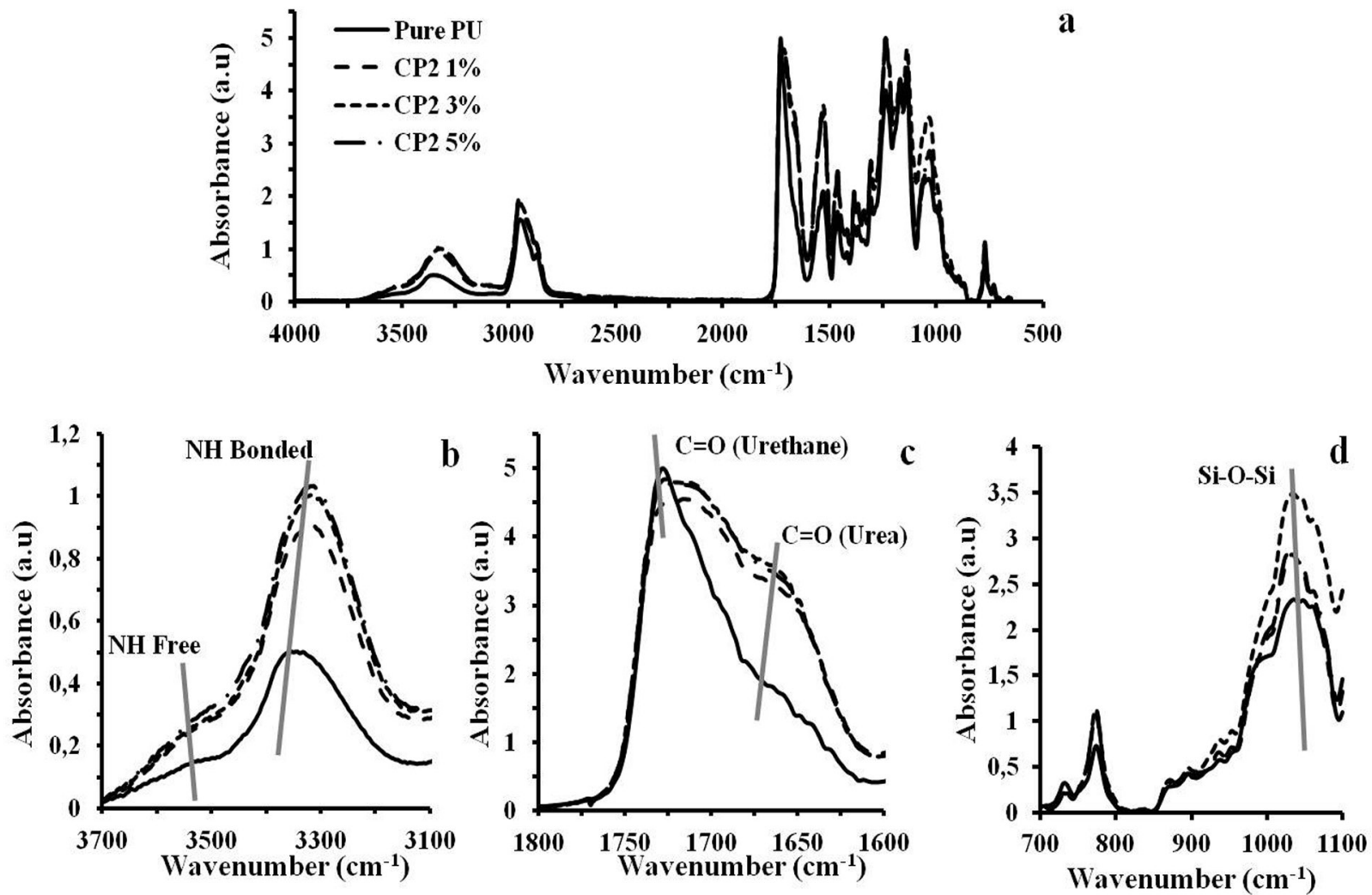

Figure 2 - FTIR spectra of the pure PU and CP2 composites (a); zoom in the region of $\mathrm{NH}$ band (b); zoom in the $\mathrm{C}=\mathrm{O}$ band and (c) zoom in the region of $\mathrm{Si}-\mathrm{OH}, \mathrm{Si}-\mathrm{O}-\mathrm{Si}$.

the silica are available and can compete with diol reacting with diisocyanate and forming a hybrid material. Thus, in the polyurethane dispersion, part of the PU chains is chemically bonded to the silica particles increasing the crosslink. This behavior is similar to the described in the literature by Chen et al. (2015). However, in the CP2 composite, is not observed the band located in $823 \mathrm{~cm}^{-1}$ (Si-OH). This can be due to the fact that silica was added in the finished WPU synthesis, leading to interactions between $\mathrm{OH}$ groups and polar groups of the polyurethane, according to literature (Baudrit et al. 2006, Bistricic et al. 2010, Gao et al. 2011, Zheng et al. 2005).

\section{THERMAL PROPERTIES}

WPU thermal degradation behavior are associated to: water elimination $\left(\approx 50^{\circ}-200^{\circ} \mathrm{C}\right)$, decomposition of the PU chain, where the first stage occurs due the hard segments degradation, i.e. urethane and urea $\left(\approx 200^{\circ}-350^{\circ} \mathrm{C}\right)$ and followed by the soft segments degradation $\left(\approx 300^{\circ}-450^{\circ} \mathrm{C}\right)$ (Han et al. 2018, Serkis et al. 2016). TGA results (Table II) show that composites presented better thermal stability when compared with WPU being more significant for CP1. TGA curves are presented in Supplementary Material, Figure S2.

As showed in Table II, the $\mathrm{T}_{10}$ values of WPU, $\mathrm{CP} 1$ and $\mathrm{CP} 2$ composites are significantly different indicating a real improvement in the thermal stability of the composites with filler addition. Furthermore, the $\mathrm{T}_{\max 1}$ and $\mathrm{T}_{\max 2}$ associated the degradation stages of the hard segments and soft segments, respectively, are well defined to the $\mathrm{CP} 2$ composites (Table II), but the $\mathrm{T}_{\max 2}$ value is inconspicuous in the WPU and in the CP1 composites. It can be seen that $\mathrm{T}_{\max 1}$ is higher in the $\mathrm{CP} 1$ and $\mathrm{CP} 2$ composites than in the WPU. 
Similar behavior to CP1 samples was also found by Bao et al. (2017) and Han et al. (2018), which describe that this increase in the thermal stability can be ascribed to a strong interaction between PU chain and silica particles. Nevertheless, unlike that described by these authors, we observed a $\mathrm{T}_{\max 2}$ of the CP2 composites (blending method). This behavior can be due the different filler-polymer interactions, where in the CP2 composites the silica particles are interacting with polar groups (i.g., ester group of the polyol), protecting the soft segments. Heck et al. (2015), found also similar result and explained that the manner in which the filler-polymer interactions depends on addition method. Moreover, the in situ method maintains the single-step degradation mechanism similar to WPU while addition by blending method promotes two-step degradation as seen in the DTG results (Supplementary Material, Figure S2).

WPU and the composites showed only glass transition temperature $\left(\mathrm{T}_{\mathrm{g}}\right)$ indicating to be an amorphous polymer. The $\mathrm{T}_{\mathrm{g}}$ values of $-56^{\circ} \mathrm{C}$ and $-52^{\circ} \mathrm{C}$ obtained for both $\mathrm{CP} 1$ and $\mathrm{CP} 2$ composites, respectively, are much lower when compared to WPU $\left(-36^{\circ} \mathrm{C}\right)$. Furthermore, a small variation between the $\mathrm{T}_{\mathrm{g}}$ of the $\mathrm{CP} 1$ and $\mathrm{CP} 2$ composites was observed. The literature shows that the addition of silica result in less direct interactions between phases, thus a higher degree of phase separation occurs between soft and hard segments of the polyurethane leading to a decrease in $\mathrm{T}_{\mathrm{g}}$ value (Baudrit et al. 2006).

\section{ACCELERATED WEATHERING TESTS}

To accelerate weathering tests was chosen the composites synthesized with $1 \%$ of filler added. The films of the WPU and composites were exposed in QUV test chamber and the accelerated weathering action on the surface of these films is presented in Figure 3a. After 403 hours, the samples were much crumbled, so it was not possible to analyze
TABLE II

Thermal properties of pure $\mathrm{PU}, \mathrm{CP1}$ and $\mathrm{CP} 2$ composites.

\begin{tabular}{cccccc}
\hline Sample & $\begin{array}{c}\mathbf{T}_{\mathbf{1 0}}{ }^{\mathbf{a}} \\
\left({ }^{\circ} \mathbf{C}\right)\end{array}$ & $\begin{array}{c}\mathbf{T}_{\mathbf{5 0}}{ }^{\mathbf{b}} \\
\left({ }^{\circ} \mathbf{C}\right)\end{array}$ & $\begin{array}{c}\mathbf{T}_{\max }{ }^{\mathbf{c}} \\
\left({ }^{\circ} \mathbf{C}\right)\end{array}$ & $\begin{array}{c}\mathbf{T}_{\max }{ }^{\mathbf{c}} \\
\left({ }^{\circ} \mathbf{C}\right)\end{array}$ & $\begin{array}{c}\mathbf{T g} \\
\left({ }^{\circ} \mathbf{C}\right)\end{array}$ \\
\hline WPU & 199 & 381 & 402 & - & -36 \\
CP1 1\% & 287 & 390 & 407 & - & -56 \\
CP1 3\% & 298 & 386 & 401 & - & -55 \\
CP1 5\% & 300 & 384 & 406 & - & -56 \\
CP2 1\% & 261 & 378 & 383 & 438 & -53 \\
CP2 3\% & 247 & 376 & 384 & 437 & -52 \\
CP2 5\% & 257 & 383 & 387 & 437 & -52 \\
\hline
\end{tabular}

${ }^{a}$ The temperatures for $10 \%$ wt degradation;

${ }^{\mathrm{b}}$ The temperatures for $50 \%$ wt degradation;

${ }^{\mathrm{c}}$ The temperatures of the maximal rate of the process.

them. Before exposure (time = zero) to QUV test, the surface of the WPU film showed smooth and homogenous, of the same way the surface of the composites films showed uniform, but with small agglomeration of silica particles. After 134 hours of exposure, all surfaces showed heterogeneous and with erosion areas. The zoom images show that the surface of $\mathrm{CP} 1$ composite film was the most crumbled, i.e. the silica incorporated in situ was not effective in resistance to accelerated aging. However, the silica added by blending method (CP2 composite) seems to have a protective role, which can be occurred due the possible filler interaction with the polymer micelles during the filler incorporation. In longer exposure times (268 and 403 hours) the films continue to be degraded, but to a minor extent to the CP2 composite. Hang et al. (2015) noticed an improvement in UV resistance of the PU coatings with the addition of small contents of $\mathrm{ZnO}$ nanoparticles and it was attributed to the UV blocking property of these nanoparticles. It was also observed an intercalation of rough/ smooth surface after 268 hours for CP1 composite and 403 hours for WPU that can be associated with a deterioration mechanism occurring in 
layers, leading to thickness loss of the films as can be seen in Figure $3 \mathrm{~b}$. The decreasing of the film thickness, during the accelerated aging test, was direct influenced by the composite obtainment method, as observed by SEM images. All films showed erosion in the surface after 134 hours exposed in QUV test leading similar thickness loss (around 15-17\%). However, in 268 hours or more it was observed a higher thickness loss for WPU ( $25 \%$ and $44 \%$, respectively) when compared with composites. When compared to the WPU and CP1, the decrease in the film thickness of CP2 was lower, i.e. when the filler is added by blending method the intermolecular filler-polymeric chain interaction improves the degradation resistance in these conditions. Unlike the composite obtained by in situ polymerization (CP1) that allowed a greater degradability of the polymer matrix due the higher chain susceptibility.

SEM (EDS mapping) and AFM micrographs of WPU and composites samples before and after accelerated aging are shown in Figure 4. In CP1 sample, it can be seen a better filler distribution on WPU matrix surface, which possible occurred due the incorporation method (in situ). However, in CP2 sample there are many filler agglomerates on the surface once that its amount is greater than in CP1 sample. This result shows that the in situ method favors the filler dispersion in the polymer. These different behaviors dependent of the addition method and are corroborated with the results of thermal stability (Supplementary Material, Figure S2) where is observed the change in the degradation mechanism. After 403 of exposure, aged CP1 shown small amount of filler (agglomerates) on the composite surface related to non aged CP1 due the degradation process of WPU matrix, which also can be seen in SEM micrographs (Figure 3). In aged $\mathrm{CP} 2$ sample, the degradation process also exposes the filler, but WPU matrix could remain almost unchanged related to non-aged CP2 sample.
Glass transition temperature ( $\mathrm{Tg}$ ) of the samples exposed in QUV test (Table III) increased when compared with the initial samples (Table II). This was an expected result since in a previous work was noticed that the increase in $\mathrm{Tg}$ can be attributed to the increase in the degree of crosslinking of components in coating leading the decrease of the mobility of the whole system (Hang et al. 2015). It was also evaluated the gloss loss (\%) of the films after exposure in QUV test. The values of gloss loss were of approximately $69 \%$ for WPU, $86 \%$ for CP1 and $41 \%$ for CP2. These drastic conditions cause the breakdown of the polymer chain and, consequently, decrease of film gloss. However the gloss loss of CP2 film was lower than the others (WPU and CP1 films) indicating that the incorporation of the $\mathrm{SiO}_{2}$ by blending method improved the UV resistance due the higher protective role this filler. This result is corroborated by the analysis of SEM (Figure 3a).

FTIR spectra of WPU, CP1 and CP2 samples before and after weathering are shown in Figure 5. It was observed changes in the structural characteristics of WPU and composites aged materials. There was the decrease of the bands intensity in $1530 \mathrm{~cm}^{-1}$ (Amide II; C-N and N-H), $1308 \mathrm{~cm}^{-1}$ (Amide III; C-N and N-H) and 1260$1200 \mathrm{~cm}-1$ (C-O stretching; acid, ester, ether and $\mathrm{C}-\mathrm{N}$ bond). In addition, it was observed the increase of the bands intensity in $1730 \mathrm{~cm}^{-1}$ (Amide I; $\mathrm{C}=\mathrm{O}$ urea, urethane and ester), $1415 \mathrm{~cm}^{-1}\left(\mathrm{CH}_{2}\right.$ adjacent to carbonyl group), $1370 \mathrm{~cm}^{-1}$ ( $\mathrm{CH}_{3}$ stretching), $1170 \mathrm{~cm}^{-1}$ (C-O stretching; ester and ether), 1050 $\mathrm{cm}^{-1}$ (C-O tertiary alcohol) and $730 \mathrm{~cm}^{-1}$ (ethyl and propyl groups). The band intensity in $1136 \mathrm{~cm}^{-1}$ band (C-O ester and ether) increased for aged WPU and decrease for both aged composites (CP1 and $\mathrm{CP} 2$ ), but the region between $1172-1050 \mathrm{~cm}^{-1}$ can be attributed to Si-O-Si bond. Besides, the increase of this region area was greater in the CP1 sample, which can indicated more exposition of the filler on the film surface and that the aging process was more aggressive for the CP1 sample. Moreover, 

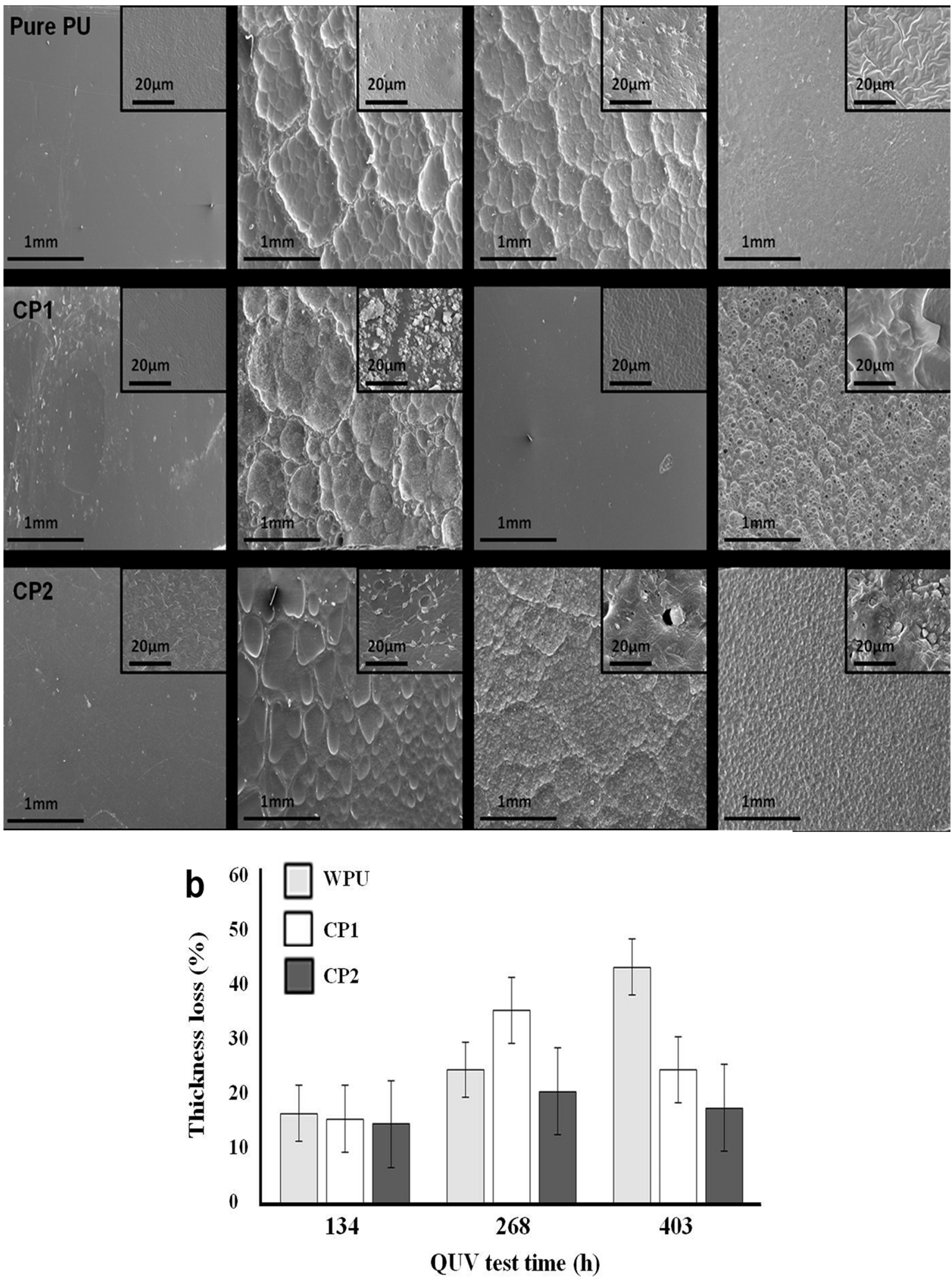

Figure 3 - (a) SEM micrographs of the samples exposed to the accelerated aging tests at a magnification of 100x; zoom at magnification 6000x and (b) Percentage loss of thickness of the films according to cycles of accelerated aging method. 


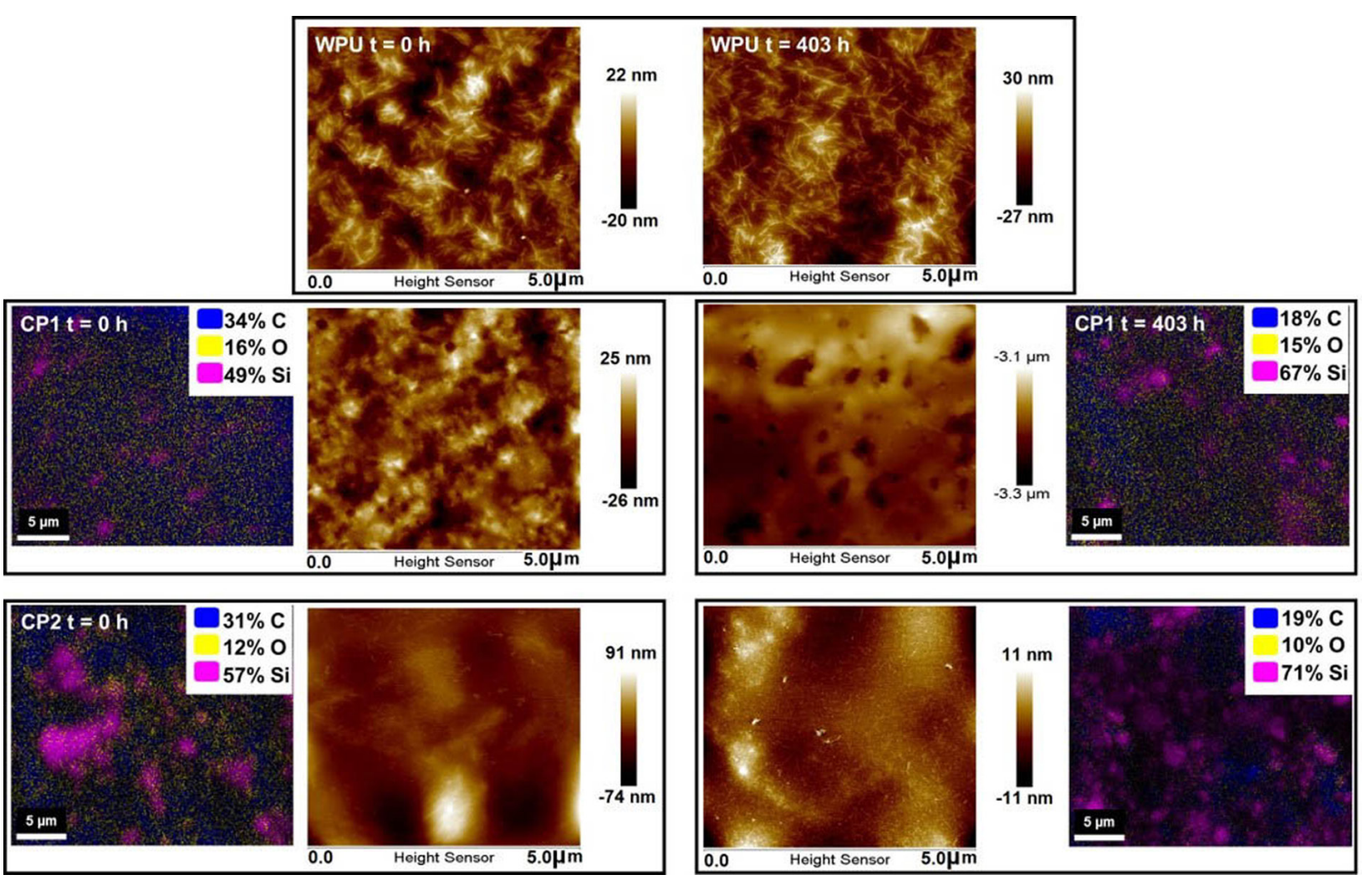

Figure 4 - EDS mapping and AFM of the samples exposed to the accelerated aging tests (Color figure can be viewed in the online issue).

there was the appearance of $801 \mathrm{~cm}^{-1}$ band in the aged composites, which is correspondent to O-Si-O (Timin et al. 2016, Lai and Li. 2017). These results are similar to found by Jacobs et al. (2016) that studied the surface degradation of a PU/nanosilica nanocomposite coating after UV exposure. They observed some changes in the FTIR spectrum of the UV exposed nanocomposite, such as the decrease in the intensity of the bands located at $1690 \mathrm{~cm}^{-}$ $1,1535 \mathrm{~cm}^{-1}$ (chain scission; amide II) and 1245 $\mathrm{cm}^{-1}$ bands. Moreover, there was the increase of bands intensity, such as in $1750 \mathrm{~cm}^{-1}$ and $1706 \mathrm{~cm}^{-}$ ${ }^{1}$ (oxidized products). All these changes occurred along of exposition time and were observed for the nanosilica/PU and pure PU sample. Also, the rate of chain scission and oxidation of the nanocomposite were lower than those of the pure PU. It indicated that the nanosilica presence has decreased the photodegradation process in the nanocomposite. This filler could provide the ability to photostabilize the PU degradation. They also observed an increase in the intensity of the band peak at $1101 \mathrm{~cm}^{-1}$ (C-O of polymer and Si-O-Si bond of the nanosilica), which can be an evidence that the filler was near of the nanocomposite surface after exposition to water (weathering process). The formation of $\mathrm{C}=\mathrm{O}$ of carboxylic acids $\left(1706 \mathrm{~cm}^{-1}\right)$ and acetyl urethane $\left(1750 \mathrm{~cm}^{-1}\right)$ are the according to the photodegradation mechanism for the esterbased PU, which propose that urethane groups are oxidized to form acetyl urethane in the presence of oxygen and UV light. This formed group can be hydrolyzed by water in order to form carboxylic acids. In addition, the ester portion degradation produces several oxidized products, such as acids and alcohol. Other interesting results were observed by Das et al. (2017a, b), who evaluated the influence of UV aging process on the performance 

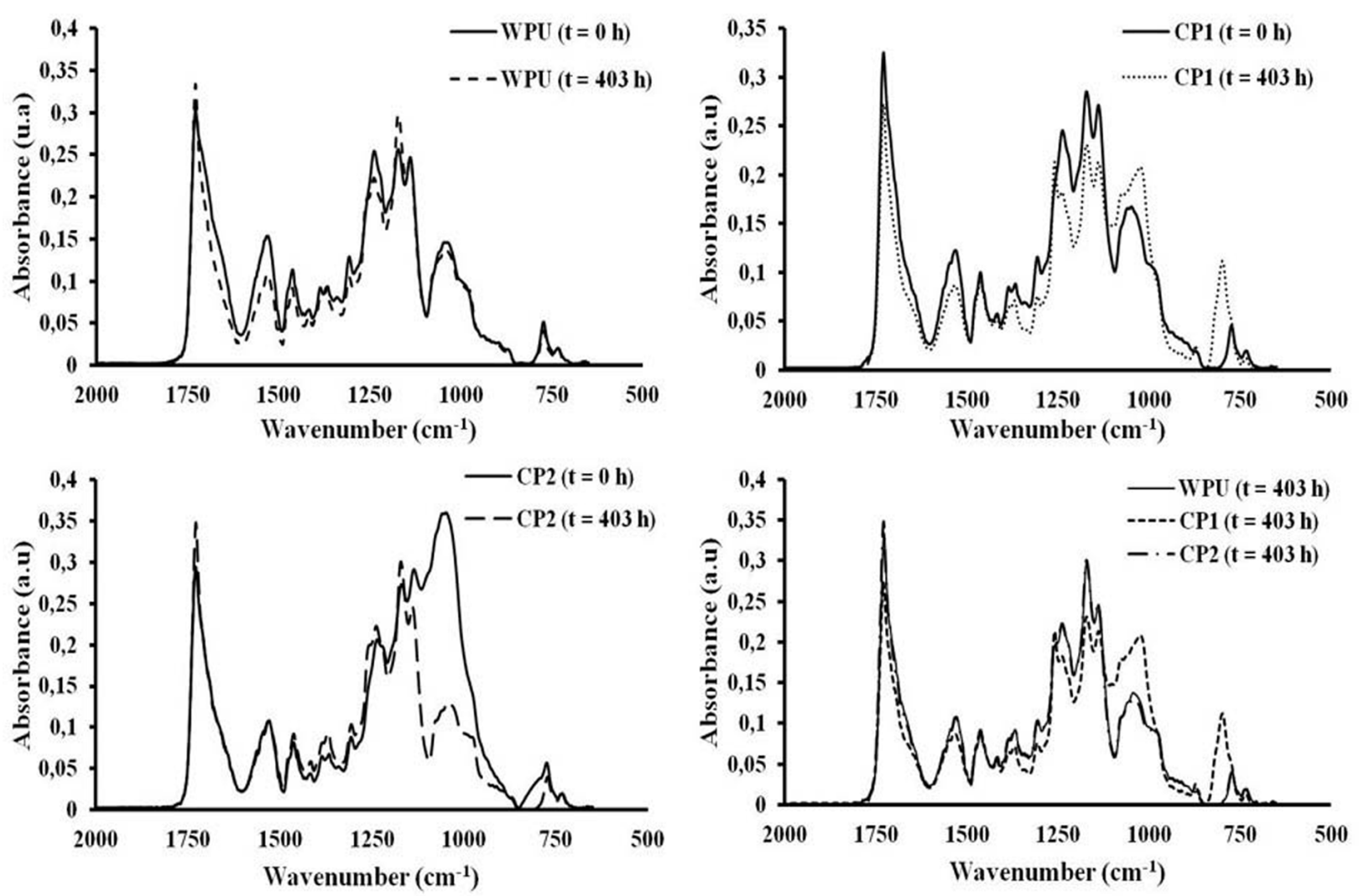

Figure 5 - FTIR spectra of the WPU and composites comparing before and after accelerated weathering.

characteristics of bio-based polyurethane after 250h of UV exposition. The researchers observed a stable decrease in the band intensity of amide I, II and III bonds (near to $1741 \mathrm{~cm}^{-1}, 1531 \mathrm{~cm}^{-1}$ and $1260 \mathrm{~cm}^{-1}$, respectively), which can demonstrate the chain scission of urethane linkages.

Moreover, the thermal stability of the aged samples was evaluated by TGA analysis (Table III), which shown that the aging process led some changes to the thermal behavior the WPU and composites samples. For WPU, after the aging exposure, there was an increase of $\mathrm{T}_{10}$ temperature, which initially demonstrated an increase in the thermal resistance. However, $\mathrm{T}_{50}$ and $\mathrm{T}_{\max }$ temperatures of aged WPU sample were less than the initial WPU temperatures. Aged CP1 sample shown similar behavior of aged WPU related to their initial samples, but when $T_{10}$ temperatures of both aged samples are compared, it can be observed small increase, which can be understood as an increase of thermal resistance due the silica presence. On the other hand aged CP2 sample shown similar behavior to the initial CP2 sample. This fact can demonstrate that, even after accelerated weathering exposure, the composite film (CP2), which filler incorporation was by blending method, can keep the thermal stability of the initial samples. Likewise, it was observed in the SEM images and the thickness loss values for the CP2 aged sample.

The weathering is one of the main factors responsible for the degradation of organic coatings such as polyurethane. Therefore, the evaluation of the film resistance to UV degradation and weathering conditions is one of the main tests for polymer (Herrera et al. 2018, Nguyen. et al. 2018). In order to improve the resistance to UV exposure, the incorporation of materials that have a broad region of UV radiation absorption into the 
TABLE III

Degradation temperatures and glass transition temperature ( $\mathrm{T}_{\mathrm{a}}$ ) of pure $\mathrm{PU}$ and $\mathrm{CP1}$ and $\mathrm{CP2}$ composites.

\begin{tabular}{ccccc}
\hline Sample & $\mathbf{T}_{\mathbf{1 0}}{ }^{\mathbf{a}}\left({ }^{\circ} \mathbf{C}\right)$ & $\mathbf{T}_{\mathbf{5 0}}{ }^{\mathbf{b}}\left({ }^{\circ} \mathbf{C}\right)$ & $\mathbf{T}_{\max }{ }^{\mathbf{c}}\left({ }^{\circ} \mathbf{C}\right)$ & $\mathbf{T g}\left({ }^{\circ} \mathbf{C}\right)$ \\
\hline WPU & 287 & 376 & 383 & -33 \\
CP1 1\% & 300 & 370 & 390 & -29 \\
CP2 1\% & 288 & 374 & 385 & -34 \\
\hline
\end{tabular}

${ }^{\mathrm{a}}$ The temperatures for $10 \% \mathrm{wt}$ degradation;

${ }^{\mathrm{b}}$ The temperatures for $50 \% \mathrm{wt}$ degradation;

${ }^{\mathrm{c}} \mathrm{The}$ temperatures of the maximal rate of the process.

polymeric matrix is one of the possibilities. Silica is considered one of the main fillers added for this purpose (Miklečić et al. 2015) and as other fillers; it can minimize the impact of UV radiation on polymer photodegradation (Monfared and Mohseni 2014). Progressive changes in PU properties and increase in $\mathrm{Tg}$ values of composites can indicated that the filler particle affects the PU matrix properties. This effect can be due the chemical or physical interactions between filler and PU matrix; and effects derived from geometrical constrains of PU matrix, which is caused by the close proximity of the $\mathrm{SiO}_{2}$ particles (Chen et al. 2015). In this work, it was possible to observe that the obtaining method of WPU/silica composites affect significantly the thermal and mainly weathering resistance these composites. The composite produced by blending incorporation method showed a good resistance to aging process when compared with in situ polymerization method.

\section{CONCLUSIONS}

Composites with silica (derived from rice husk ash) and waterborne polyurethane were successfully prepared by two methods, in situ polymerization and blending method. The results presented in this work showed that the addition of $1 \%$ of silica by blending method led to the composites with better resistance to thermal degradation and accelerated weathering. These results are associated to interaction kind between filler and polymer micelles leading to interactions intermicellar. Moreover, $\mathrm{SiO}_{2}$ particles derived from rice husk ash are cheap reinforcement materials and blending method is a simple technique to obtain theses composites. These two factors facilitate the composite production in large-scale to WPU manufactures.

\section{ACKNOWLEDGMENTS}

The authors thank Financiadora de Estudos e Projetos (FINEP) for funding, PUCRS and Conselho Nacional de Desenvolvimento Científico e Tecnológico (CNPq) by scholarships and NokXeller Microdispersions for the donation of raw materials. RL and SE thank $\mathrm{CNPq}$ for Technological Development-DT scholarship. This study was financed in part by the Coordenação de Aperfeiçoamento de Pessoal de Nivel Superior Brasil (CAPES) - Finance Code 001.

\section{AUTHOR CONTRIBUTIONS}

Wesley F. Monteiro contributed to the synthesis and characterizations of the nanocomposites; Gabriela M. Miranda and Claudia, A. B. dos Santos contributed with the accelerated weathering test; Rafael R. Soares, Carlos L.P. Carone, Viviane de Lima and Adriano D. Campani contributed to the synthesis and characterizations of waterborne polyurethanes; Maurício S. Hoffmann contributed with the morphological characterization of nanocomposites; Prof. Milton F. de Souza contributed to the synthesis of silica from rice husk ash. Professors Sandra M. O. Einloft, Jeane E. de Lima, and Rosane A. Ligabue contributed in all stages of this study.

\section{REFERENCES}

BAO Y, WANG T, KANG Q, SHI C AND MA J. 2017. Micelletemplate synthesis of hollow silica spheres for improving water vapor permeability of waterborne polyurethane membrane. Sci Rep 7: 1-14. 
BAȘTÜRK E, MADAKBAȘ S AND KAHRAMAN MV. 2016. Improved Thermal Stability and Wettability Behavior of Thermoplastic Polyurethane/Barium Metaborate Composites. Mater Res 19(2): 434-439.

BAUDRIT JV, BAÑON VN, VÁZQUEZ P AND MARTÍNEZ JMM. 2006. Addition of nanosilica with different silanol content to thermoplastic polyurethane adhesives. Int J Adhes Adhes 26(5): 378-387.

BISTRICIC L, BARANOVIC G, LESKOVAC M AND BAJSIC EG. 2010. Hydrogen bonding and mechanical properties of thin films of polyether-based polyurethanesilica composites. Eur Polym J 46(10): 1975-1987.

BHARGAVA S, KUBOTA M, LEWIS R, ADVANI S, PRASAD A AND DEITZEL J. 2015. Ultraviolet, water, and thermal aging studies of a waterborne polyurethane elastomer-based high reflectivity coating. Prog Org Coat 79: 75-82.

CAKIC SM, RISTIC IS, CINCOVIC MM, STOJILJKOVIC DT AND SIMENDIC JB. 2016. Preparation and characterization of waterborne polyurethane/silica hybrid dispersions from castor oil polyols obtained by glycolysis poly (ethylene terephthalate) waste. Int J Adhes Adhes 70: 329-341.

CHAI CP, MA YF, LI GP, GE Z, MA SY AND LUO YJ. 2018. The Preparation of High Solid Content Waterborne Polyurethane by Special Physical Blending. Prog Org Coat 115: 79-85.

CHEN L, WANG X, JIA Z, LUO Y AND JIA D. 2015. Use of precipitated silica with silanol groups as an inorganic chain extender in polyurethane. Mat Des 87: 324-330.

DAS S, PANDEY P, MOHANTY S AND NAYAK SK. 2017a. Investigation into the Influence of UV Aging on Green Polyurethane/Nanosilica Composite Coatings Based on Transesterified Castor Oil and Palm Oil Isocyanate. J Inorg Organomet Polym 27(3): 641-657.

DAS S, PANDEY P, MOHANTY S AND NAYAK SK. $2017 \mathrm{~b}$. Study of UV aging on the performance characteristics of vegetable oil and palm oil derived isocyanate based polyurethane. Korean J Chem Eng 34(2): 523-538.

FAN W, DU W, LI Z, DAN N AND HUANG J. 2015. Abrasion resistance of waterborne polyurethane films incorporated with PU/silica hybrids. Prog Org Coat 86: 125-133.

FIORELLI J, SARTORI DL, CRAVO, JCM, JUNIOR HS, ROSSIGNOLO JA, NASCIMENTO MF AND LAHR FAR. 2016. Sugarcane Bagasse and Castor Oil Polyurethane Adhesive-based Particulate Composite. Mater Res 16: 439-446.

GAO X, ZHU Y, ZHAO X, WANG Z, AN D, MA Y, GUAN S, DU Y AND ZHOU B. 2011. Synthesis and characterization of polyurethane/ $\mathrm{SiO}_{2}$ composites. Appl Surf Sci 257(10): 4719-4724.

GURUNATHAN T AND CHUNG JS. 2017. Synthesis of Aminosilane Crosslinked Cationomeric Waterborne
Polyurethane Nanocomposites and its Physicochemical Properties. Colloids Surf A Physicochem Eng Aspects 522: 124-132.

HAN Y, HU J AND XIN Z. 2018. In-Situ Incorporation of Alkyl-Grafted Silica into Waterborne Polyurethane with High Solid Content for Enhanced Physical Properties of Coatings. Polym 10: 1-15.

HANG TTX, DUNG NT, TRUC TA, DUONG NT, TRUOC BV, VU PG, HOANG T, THANH DTM In-Situ Incorporation of Alkyl-Grafted Silica into Waterborne Polyurethane with High Solid OLIVIER MG. 2015. Effect of silane modified nano $\mathrm{ZnO}$ on UV degradation of polyurethane coatings. Prog Org Coat 79: 68-74.

HECK CA, DOS SANTOS JZ AND WOLF CR. 2015. Waterborne polyurethane: the effect of the addition or in situ formation of silica on mechanical properties and adhesion. Int J Adhes Adhes 58: 13-20.

HEIDARIAN M, SHISHESAZ MR, KASSIRIHA SM AND NEMATOLLAHI M. 2010. Characterization of structure and corrosion resistivity of polyurethane/ organoclay nanocomposite coatings prepared through anultrasonication assisted process. Prog Org Coat 68: 180188.

HERRERA R, SANDAK J, ROBLES E, KRYSTOFIAK T AND LABIDI J. 2018. Weathering resistance of thermally modified wood finished with coatings of diverse formulations. Prog Org Coat 119:145-154.

JACOBS D, HUANG S, CHENG Y, RABB S, GORHAM J, KROMMENHOEK P, YU L, NGUYEN T AND SUNG L. 2016. Surface Degradation and Nanoparticle Release of a Commercial Nanosilica/Polyurethane Coating Under UV Exposure. J Coat Technol 13(5): 735-751.

JOFRE-RECHE J, FUENSANTA M, YÁÑEZ-PACIOS A, COLERA M, RODRIGUEZ F, IGLESIAS I, COSTA V AND MARTÍN-MARTÍNEZ J. 2017. Improvement in Adhesion, Abrasion Resistance, and Aging of Polyurethane Coatings Prepared with Polycarbonate Diol for Internal Pipelines. J Mater Civ Eng 29(10): 1-5.

LAI SM AND LI PW. 2017. Effect of thermoplastic polyurethane-modified silica on meltblended poly(lactic acid) (pla) nanocomposites. Polym Polym Compos 25: 583-592.

LI R AND SHAN Z. 2018. Research for waterborne polyurethane/composites with heat transfer performance: a review. Polym Bull 1-14.

LIAO H, ZHANG B, HUANG L, MA D, JIAO Z, XIE Y, TAN S AND CAI X. 2015. The utilization of carbon nitride to reinforce the mechanical and thermal properties of UVcurable waterborne polyurethane acrylate coatings. Prog Org Coat 89: 35-41.

LV Z, LI X AND YU X. 2012. The effect of chain extension method on the properties of polyurethane/ $\mathrm{SiO} 2$ composites. Mat Des 35: 358-362. 
MIKLEČIĆ J, BLAGOJEVIĆ SL, PETRIČ M AND RAJKOVIĆ VJ. 2015. Influence of $\mathrm{TiO}_{2}$ and $\mathrm{ZnO}$ nanoparticles on properties of waterborne polyacrylate coating exposed to outdoor conditions. Prog Org Coat 89: 67-74.

MONFARED AS AND MOHSENI M. 2014. Polyurethane nanocomposite films containing nano-cerium oxide as UV absorber; Part 2: Structural and mechanical studies upon UV exposure. Colloids Surf A: Physicochem Eng Aspects 441: 752-757.

MONTEIRO WF, SANTOS, CAB, EINLOFT S, OBERSON M, CARONE CLPAND LIGABUE RA. 2016. Preparation of modified titanate nanotubes and its application in polyurethane nanocomposites. Macromol Symp 368: 9397.

MONTEIRO WF, SANTOS CAB, HOFFMANN MS, CARONE CLP, EINLOFT SMO, SOUZA MO AND LIGABUE RA. 2018. Modified titanate nanotubes for the production of novel aliphatic polyurethane nanocomposites. Polym Comp 40(6): 2292-2300.

NGUYEN T, LE X, DAO P, DECKER C AND NGUYEN-TRI PJ. 2018. Stability of acrylic polyurethane coatings under accelerated aging tests and natural outdoor exposure: The critical role of the used photo-stabilizers. Prog Org Coat 124: $137-146$

PÁCIOS VG, RECHE JAJ, COSTA V, COLERA M AND MATÍNEZ JMM. 2013. Coatings repared from waterborne polyurethane dispersions obtained with polycarbonates of 1,6-hexanediol of different molecular. Prog Org Coat 76: 1484-1493.

PERUZZO PJ, ANBINDER PS, PARDINI FM, PARDINI OR, PLIVELIC TS AND AMALVY JI. 2016. On the strategies for incorporating nanosilica aqueous dispersion in the synthesis of waterborne polyurethane/silica nanocomposites: Effects on morphology and properties. Mat Today Commun 6: 81-91.

PRADO MA, DIAS G, CARONE C, LIGABUE R, DUMAS A, ROUX CL, MICOUD P, MARTIN F AND EINLOFT S. 2015. Synthetic Ni-talc as filler for producing polyurethane composites. J Appl Polym Sci 132(16): 1-8.

REN D AND FRAZIER CE. 2013. Structure-property behavior of moisture-cure polyurethane wood adhesives: Influence of hard segment content. Int J Adhes Adhes 45: 118-124.

SADEGHI M, TALAKESH MM, GHALEI B and SHAFIEI M. 2013. Preparation, characterization and gas permeation properties of a polycaprolactone based polyurethane-silica nanocomposite membrane. J Membr Sci 427: 21-29.

SERKIS M, ŠPÍRKOVÁ M, HODAN J AND KREDATUSOVÁ J. 2016 Nanocomposites made from thermoplastic waterborne polyurethane and colloidal silica. The influence of nanosilica type and amount on the functional properties. Prog Org Coat 101: 342-349.

SEYFI J, HEJAZI I, JAFARI SH, KHONAKDAR HA AND SIMON F. 2016. Enhanced hydrophobicity of polyurethane via non-solvent induced surface aggregation of silica nanoparticles. J Colloid Interface Sci 478: 117-126.

SOARES RR, CARONE C, EINLOFT S, LIGABUE R AND MONTEIRO WF. 2014. Synthesis and characterization of waterborne polyurethane/ZnO composites. Polym Bull 71: 829-838.

SUNG G AND KIM JH. 2017. Influence of filler surface characteristics on morphological, physical, acoustic properties of polyurethane composite foams filled with inorganic fillers. Compos Sci Technol 146: 147-154.

THOMAS S, DATTA J, HAPOMIUK J AND REGHUNADHAN A. 2017. Polyurethane Polymers: Composites and Nanocomposites, $1^{\text {st }}$ ed., Amsterdam: Elsevier, $634 \mathrm{p}$.

TIMIN AS, SOLOMONOV AV, KUMAGAI A, MIYAWAKI A, KHASHIROVA SY, ZHANSITOV A AND RUMYANTSEV E. 2016. Magnetic polymer-silica composites as bioluminescent sensors for bilirubin detection. Mat Chem Phys 183: 422-429.

YANG W, CHENG X, WANG H, LIU Y AND DU Z. 2017. Surface and mechanical properties of waterborne polyurethane films reinforced by hydroxil-terminated poly(fluoralkil methacrylates. Polym 133: 68-77.

YU F AND HUANG HX. 2015. Simultaneously toughening and reinforcing poly(lactic acid)/ thermoplastic polyurethane blend via enhancing interfacial adhesion by hydrophobic silica nanoparticles. Polym. Test 45: 107-113.

ZHANG SW, REN L, JIANG J, YANG C, CHEN M AND LI X. 2011. Facile synthesis of waterborne UV-curable polyurethane/silica nanocomposites and morphology, physical properties of its nanostructured films. Prog Org Coat 70: 1-8.

ZHENG J, OZISIK R AND SIEGEL RW. 2005. Disruption of self-assembly and altered mechanical behavior in polyurethane/zinc oxide composites. Polym 46(24): 10873-10882.

\section{SUPPLEMENTARY MATERIAL}

Figure S1 - SEM images of the SiO2 filler (a) 60x and (b) 100000x.

Figure S2 - Results of (a,c) TGA and DTG of CP1; (c,d) TGA and DTG of CP2. 